\title{
EXPLORING THE POTENTIAL OF TRAFFIC INDEX DATA TO ANALYZE ESSENTIAL TRAFFIC IMPACT IN DEVELOPING CITIES
}

\author{
T. Moyo ${ }^{\mathrm{a}, *}$, A. Kibangou ${ }^{\mathrm{b}}$, W. Musakwa ${ }^{\mathrm{c}}$ \\ ${ }^{a}$ Dept. of Quality and Operations Management, University of Johannesburg, Doornfontein Campus, 0184 Johannesburg, South Africa \\ b Université Grenoble Alpes, Domaine Universitaire - BP46, 38402 Saint Martin d'Hères, France \\ ${ }^{c}$ Future earth and Ecosystem Services Research Group, University of Johannesburg, Doornfontein, 0184 Johannesburg, South Africa
}

KEY WORDS: Essential Traffic, Emission, Congestion, COVID-19, Traffic index, Johannesburg

\begin{abstract}
:
In developing countries, metropolitan cities, due to their economic activities, attract an increasing amount of commuters on a daily basis. This has led to major freeways and roads experiencing high levels of congestion and consequently high pollution levels. In 2020 , due to a global pandemic of an outbreak of Corona Virus (COVID-19), the national government declared a national shutdown with only essential traffic being allowed to operate. Given the scenario of the national lock-down this allows for the statistical analysis of the impact of essential traffic on the overall transportation system. Consequently the aim of the paper was to assess the congestion and $\mathrm{CO}_{2}$ emission impact of essential traffic for the City of Johannesburg. Using an exploratory approach, we monitored and collected traffic congestion data from the Tomtom traffic index for the metropolitan city of Johannesburg, South Africa. We develop a relationship between congestion and pollution to visualise the daily variations in pollution and congestion levels. We demonstrate this by comparing variations in congestion levels in two epochs, viz the period without movement restrictions and the period whereby movement is restricted. The results reveal essential traffic on the congestion index to be below 22 percent for both weekends and weekdays. A scenario common only during weekends in 2019. Whilst for the emission index, $\mathrm{CO}_{2}$ levels are approximately less than 45 percent throughout the week. The paper concludes the investment into mining and analysing traffic data has a significantly role for future mobility planning in both the developed and developing world and, more generally, improving the quality of commuting trips in the city.
\end{abstract}

\section{INTRODUCTION}

Operation efficiency and environmental preservation have over the years become priorities in mobility planning. The growth in Intelligent Transportation Systems (ITS) has enhanced the way mobility in contemporary cities is managed. In 2020 a global pandemic of the coronavirus (COVID-19) led to many countries closing down their economic operations (World.Health.Organization, 2020). The virus spreads mainly through respiratory droplets which are transferred to another individual through close personal contact. To limit the spread of the virus and control transmission rates to allow health practitioners to improve health care systems, national governments have restricted movement rights of citizens. Due to this limitation only essential traffic is permitted during lock-down. From an operational perspectives this allows traffic authorities to assess the statistical impact of essential traffic on the overall transportation system. Operational efficiency can be evaluated in terms of the congestion index and environmental preservation in terms of the emission index.

Generally, traffic congestion can be defined as the additional travel time taken by vehicles when they traverse over a given spatial location when compared to the free-flowing travel time (Zhao and $\mathrm{Hu}, 2019$ ). It can be induced by micro-level factors (relating to current conditions of roads) and macro-level factors (relating to demand for road usage) (Rao and Rao, 2012, Polzin, 2017). Lock-down reduces the demand for road usage to essential demand whose impact deserves to be analyzed. Nowadays, based on travel time measurements, congestion can be characterized by traffic operators through a traffic index; e.g. TomTom Trafiif index.

Emissions due to traffic can be derived using either macroscopic,

\footnotetext{
*Corresponding author-thembanijoel@gmail.com
}

microscopic, or mesoscopic models. Such models rely on either observed vehicle engine, vehicle acceleration data or standard emission coefficients to monitor emissions (Othman et al., 2019). They are not directly related to the congestion index. It is therefore important to fill this gap to allow joint monitoring and analysis of congestion and emissions.

Traffic index data promises to assist transportation planners in both developed and developing countries with reliable information to inform mobility models which inform decision making (Furtlehner et al., 2010). Consequently the aim of the paper was to assess the congestion and $\mathrm{CO}_{2}$ emission impact of essential traffic for the City of Johannesburg. The paper is organized as follows, section 2. positions the paper with regards to existing literature; section 3. introduces the study area; section 4. describes the methodology and the congestion index and emission index; section 5. illustrates the results and their implementation to urban mobility; lastly section 6 . concludes the paper and presents recommendations.

\section{RELATED WORK}

\subsection{Congestion measurement}

Generally congestion is measured as a ratio of volume-to-capacity In mobility studies the best practice appears to be using accessible data resources within an analysis framework that can eventually capture the trends within the transportation systems (Michalopoulos and Pisharody, 1981) (Liu et al., 2009). Vehicle queues at intersections are expressed as a function of traffic capacity and demand. Such a framework is normally utilised at traffic-controlled intersections to ensure a constant average of permissible congestion is allowed to ensure a balance between the traffic jammed flow and capacity flow (Michalopoulos and Pisharody, 1981). 
Other congestion estimates studies have sought to detect queue lengths in real-time using location or trajectory data of probe vehicles. (Bremmer et al., 2004) proposed using operational data collected from sensors placed along major highways to estimate traffic volumes and speeds. These sensors were used to gather vehicle count and travel time data between sensors. Findings from the analysis were to be able to distinguish between recurring congestion (moderately acceptable congestion triggered by routine traffic volumes operating in a typical setting) and nonrecurring congestion (unforeseen congestion triggered by unpredictable actions such as inclement weather or traffic accidents) at real-time. (Dias et al., 2009) proposed to measure real-time congestion one should consider:

$$
C=\frac{V_{f}-V}{V_{f}}
$$

where $C$ represents Congestion, $V_{f}$ free flow speed and $V$ the average speed in the network. To calculate actual travel speeds, detectors are used. These can be placed at pre-defined locations along roads or by monitoring the Global Positioning System (GPS) signal from vehicles. Mounting speed detectors along roads although expensive allows for city authorities to be able to collect ground true data on major roads. (Alexander and González, 2015) estimated travel patterns by extracting the average daily origindestination trips from mobile phone records. Findings from the study reveal the modal shift to ride-share services has the potential to significantly reduce congestion on major roads. However this varies spatially and temporally, as it is subject to the distribution of trips and mode shares. The methods used in these studies have been effective in disseminating and sharing the traffic congestion trends for various spatial locations. However, they are limited to the specific spatial locations as setting up sensors along roads maybe hindered by privacy concerns. Based on such a situational assessment, additional sources of travel pattern data have been inco-operated by other studies and traffic agencies. The following simplified function $\epsilon$ congestion index is expressed as the ratio of extra travel time $\Delta T$ with respect to the free flow travel time $T_{f}$ :

$$
\epsilon=\frac{\Delta T}{T_{f}}
$$

Using a algebraic operations we then link the average speed $V$ with the free flow speed $V_{f}$ as

$$
\frac{V_{f}}{V}=1+\epsilon
$$

One can easily show that the two indexes are related as:

$$
\epsilon=\frac{C}{1-C}
$$

which is well defined since $C \neq 0$.

Numerous third party-companies now offer on-board navigation systems that use the GPS collectively with unique routing software. The principal operation of these navigation systems is to guide the driver by suggesting the shortest distance or shortest duration between an origin and destination. The data from these trips presents an unprecedented mine to unpack city mobility trends. A notable example is Tomtom (a company that provides location technology and consumer technologies), which has developed a real-time congestion index based on such GPS data from vehicles and sensors along major roads. This presents a robust data resource which researchers and city authorities can utilise to analyse and visualise mobility trends over time. The growth in such open source platforms promises to create new opportunities, of congestion analysis, in this paper we hence utilise data from the traffic index as an input to unpack traffic trends for the city of Johannesburg.

\subsection{Emission measurement}

Contemporary research to mitigate problems emanating from the transportation systems has rapidly grown. Globally the dominant anthropogenic sources of air pollution have been emissions from vehicular transportation (Arkatkar, 2018). Gathering traffic flow information is essential for traffic management systems, however data collection can be difficult. For example in locations such as India, highways are characterised with having vehicles with highly varying physical dimensions and speeds namely buses, tuk-tuks, private vehicles and bicycles (Arkatkar, 2018). Hence articulating traffic volume as the quantity of vehicles passing a given location on the highway per unit time would be inadequate as numerous vehicles with varying static and dynamic features would not be included in the traffic assessment.The proliferation of vehicle emission estimation models has promises to play a vital role in emission control at both city and regional level (Zegeye et al., 2009). Consequently scholars have utilised sensors and GPS data to calculate traffic flow (Wang and Fu, 2010).

Due to the high volumes of vehicles in urban areas a vast body of mobility research has been developed to measure and evaluate the pollutants exhaust emissions from vehicles (Boriboonsomsin et al., 2012, Song et al., 2013). As the reduction and estimation of these emissions will led to a better quality of life in urban areas. In (Boriboonsomsin et al., 2012, Song et al., 2013) the authors derive Energy/Emissions Operational Parameter Set (EOPS) from a large data set of speed profiles with each record with characteristics of time, geographic location and travelling speed. We will resort to such averaged models models.

\section{STUDY AREA}

The Metropolitan City of Johannesburg is the economic hub of the wealthiest province, Gauteng in South Africa (see Figure 1).

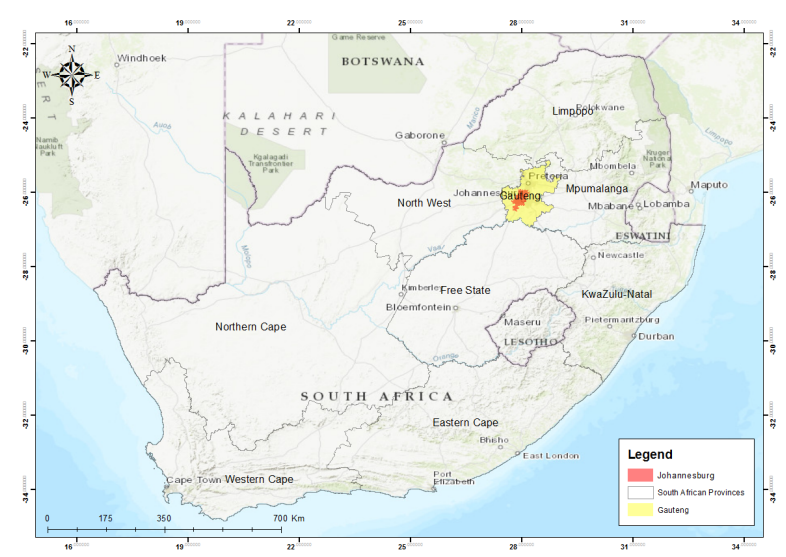

Figure 1: Study Area

Due to these economic activities, many people traverse this city on a daily basis seeking greener pastures. This has led to major freeways and roads experiencing high levels of congestion. In 2020, due to a global pandemic of an outbreak of Corona Virus (COVID-19), the national government declared a national shut down on the 23 of March 2020 which only came into effect on 
the 26 of March 2020 (Gilbert et al., 2020). As part of the shutdown, movement between provinces, metros and district areas was banned. To facilitate movement by essential workers public transport for essential trips was restricted, in the morning between 05:00 to 09:00 and evening between 16:00 to 20:00. On the 1st of April 2020 the passenger loading capacity on vehicles was revised from 50 percent to 70 percent (Nyabadza et al., 2020). Table 1 summarises the timeline of movement restrictions imposed in South Africa since the first reported COVID-19 case. In the paper we hence seek to visualise mobility trends that have occurred due to such restriction to travel in the city of Johannesburg.

Table 1: COVID-19 Movement Restriction Timeline in South Africa

\begin{tabular}{|c|c|}
\hline Date & Event \\
\hline March 5 & First recorded COVID-19 case in South Africa \\
March 15 & President declares a national state of disaster \\
March 16 & Ports of entry and exist closed \\
March 18 & Travel ban to and from high-risk countries \\
March 26 & National lock-down \\
April 1 & Public transportation operations revised \\
\hline
\end{tabular}

Mobility within the Gauteng province has decreased after the lock-down (see Figure 2). In particular, trends in retail and recreation -70 percent and Grocery and pharmacy -39 percent are comparable, with a spike due to panic-buying before the commencement of the lock-down. Essential traffic from essential workers can be observed with movement for residential trips at +24 percentage and workplace at 43 percent (Google, 2020).

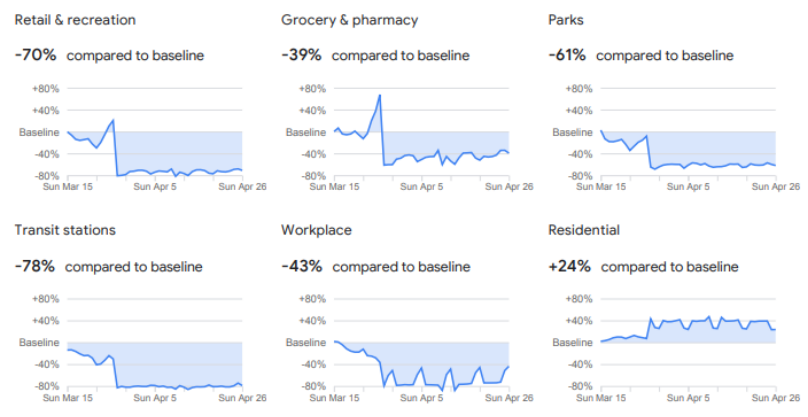

Figure 2: Community Mobility

\section{METHODOLOGY}

We use the Tomtom Traffic Index $\epsilon$ for the City of Johannesburg, South Africa for a one week period from 14/04/2020 to 20/04/2020 and compare this data with the previous year in 2019 for the same time period 14/04/2019 to 20/04/2019.

To evaluate $\mathrm{CO}_{2}$ emissions, we resort to model emission of light vehicles developed in (Song et al., 2013):

$$
E(V)=\frac{a}{V}+\sum_{k=0}^{2} \beta_{k} V^{k},
$$

where $V$ stands for the average speed, parameters $a$ and $\beta_{k}$ being given by $a=4780, \beta_{0}=111, \beta_{1}=-1.24$ and $\beta_{2}=$ $2.37 \times 10^{-2}$. This function is convex and has a single minimum for $V>0$ denoted as $E_{m}$. In the sequel $V_{m}$ stands for the corresponding average speed; $E\left(V_{m}\right)=E_{m}$, and $\epsilon_{m}$ the congestion level corresponding to $V_{m}$. We can make emissions explicitly dependent on the congestion index and the the free-flow speed as follows:

$$
E\left(\epsilon, V_{f}\right)=\frac{a(1+\epsilon)}{V_{f}}+\sum_{k=0}^{2} \beta_{k} \frac{(1+\epsilon)^{k}}{V_{f}^{k}}
$$

With these notations, we define the $\mathrm{CO}_{2}$ emission index as

$$
\gamma\left(\epsilon, V_{f}\right)=\frac{E\left(\epsilon, V_{f}\right)}{E_{m}}-1
$$

Given the city of Johannesburg road network which consists in urban arterial and highways we limit the free-flow speed to 50 $\mathrm{Km} / \mathrm{hr}$. The explicit model is then given by:

$$
\gamma(\epsilon, 50)=0.0269+0.4752 \epsilon-\frac{0.3082}{1+\epsilon}+\frac{0.2945}{(1+\epsilon)^{2}}
$$

\section{RESULTS}

\subsection{Analysis of congestion}

Figure 3 depicts the variations in congestion levels in two epochs: the period without movement restrictions and the period whereby movement is restricted. In 2019 according to the Tomtom Traffic Congestion Index for the city of Johannesburg. Figure 3 for

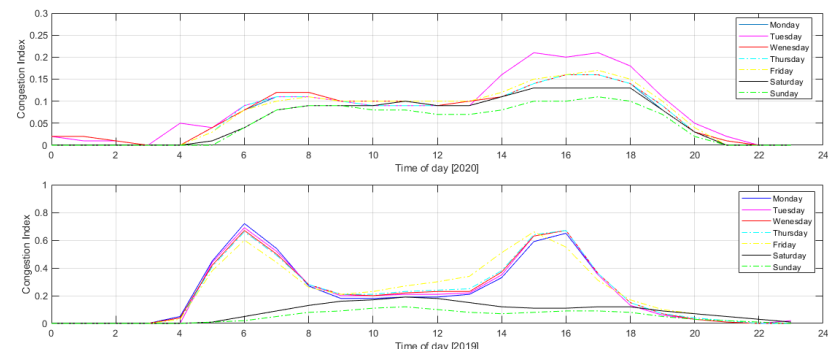

Figure 3: 2019 Average congestion index (bottom) vs congestion index during lock-down (top)

weekdays congestion averaged between 28 percent to 69 percent during the morning peak hour 06:00 to $08: 00$ and 59 percent to 13 percent during the afternoon peak hour between 15:00 to 18:00. For weekends congestion averaged between 2 percent to 13 percent during the morning peak hour 06:00 to 08:00 and 8 percent to 12 percent during the afternoon peak hour between 15:00 to 18:00. This statistic is important in estimating the impact the national shutdown has had on congestion in the city. It is important to note that at the beginning of the epidemic, mobility in the country was considered uninterrupted even through concerns over the global impact of COVID-19 were present. The data from the Tomtom Traffic Congestion Index was then collected and visualised for the period from the 14/04/2020 to 20/04/2020 approximately 18 days after the declaration of a national shutdown.

Figure 4 depicts an abrupt change in congestion trends in the city. For weekdays congestion averaged between 8 percent to 12 percent during the morning peak hour 06:00 to 08:00 and 11 percent to 21 percent during the afternoon peak hour between 15:00 to 18:00. For weekends congestion averaged between 1 percent to 8 percent during the morning peak hour 06:00 to 08:00 and 1 percent to 13 percent during the afternoon peak hour between 15:00 to 18:00. The uniqueness of the trend in the 2020 data is that congestion levels are all below 22 percent for both weekdays and weekends. A scenario common only during weekends in 2019. The low levels in congestion trends in 2020 between weekdays and weekends could be due to the restricted movement with only 


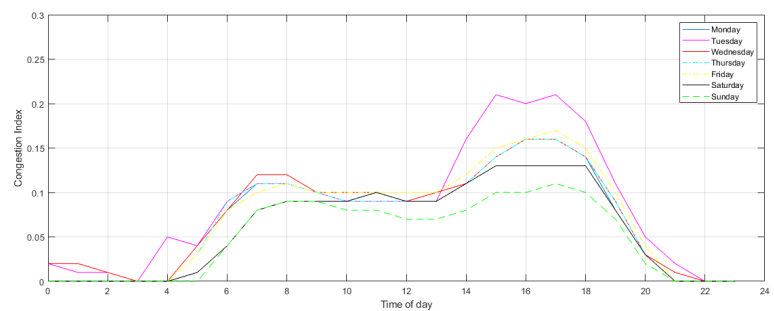

Figure 4: Time evolution of Congestion index during a lock-down week

movement deemed essential being allowed. Also, as part of the lock-down restrictions most trips in the city can be described as short trips, that is between home and the local commercial shops, which generally do not result in high congestion.

\subsection{Analysis of $\mathrm{CO}_{2}$ emissions}

The Emission Index is a useful tool for assessing emission rates and informing city planners on possible deterring measures. Figure 5 summarise the trends in $\mathrm{CO}_{2}$ emissions during the lockdown period in 2020. We can note a similar distribution trend than for congestion.
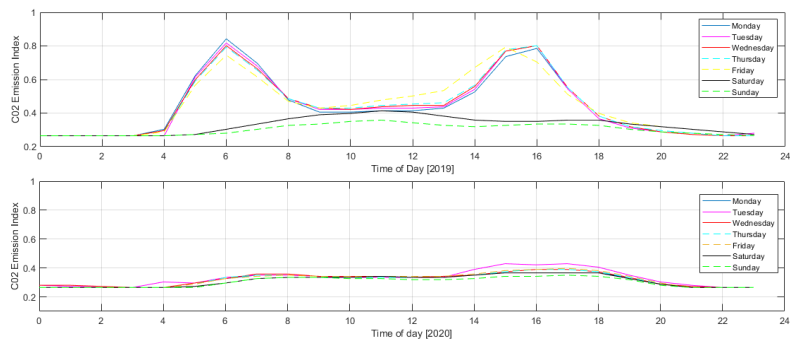

Figure 5: $\mathrm{CO}_{2}$ emission index: 2019 Average trends (top) vs lock-down (bottom)

Figure 5 in 2019 for weekdays emission averaged between 81 percent to 48 percent during the morning peak hour 06:00 to 08:00 and 79 percent to 37 percent during the afternoon peak hour between 15:00 to 18:00. For weekends emission averaged between 21 percent to 39 percent during the morning peak hour 06:00 to $08: 00$ and 38 percent to 36 percent during the afternoon peak hour between 15:00 to 18:00. Given how most trips made during the weekend are for recreational purposes the general distribution of emission levels is even throughout the day. For

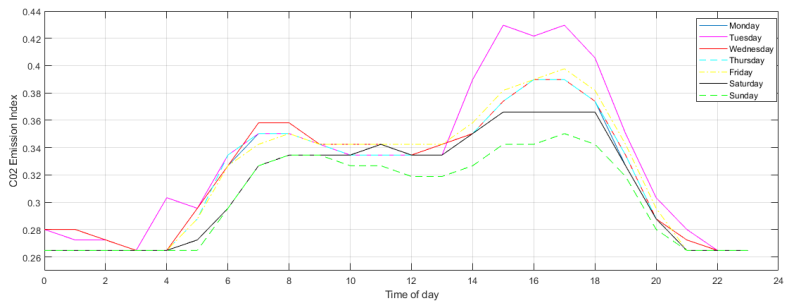

Figure 6: Time evolution of $\mathrm{CO}_{2}$ emission index

the data between $14 / 04 / 2020$ to $20 / 04 / 2020$ emission is approximately less than 45 percent through the week, this trend is similar to the congestion index (see Figure 6). For weekdays emissions averaged between 33 percent to 35 percent during the morning peak hour 06:00 to 08:00 and 34 percent to 43 percent during the afternoon peak hour between 15:00 to 18:00. For weekends congestion averaged between 29 percent to 33 percent during the morning peak hour 06:00 to 08:00 and 33 percent to 37 percent during the afternoon peak hour between 15:00 to 18:00.

To compare variations and similarities between the two trends in the two years 2019 and 2020 we use a cumulative distribution plot. In 2019, the days can clearly be clustered into two categories weekend and weekdayss. For the weekend, approximately 90 percent of time the emission index is below is 38 percent. The contribution of the national lock-down to reducing emission can best be visualised by Figure 8 in comparison with the previous year. For all days of the week $\mathrm{CO}_{2}$ emission is below 0.4 . We can conclude that essential traffic has an emission index below 0.4.

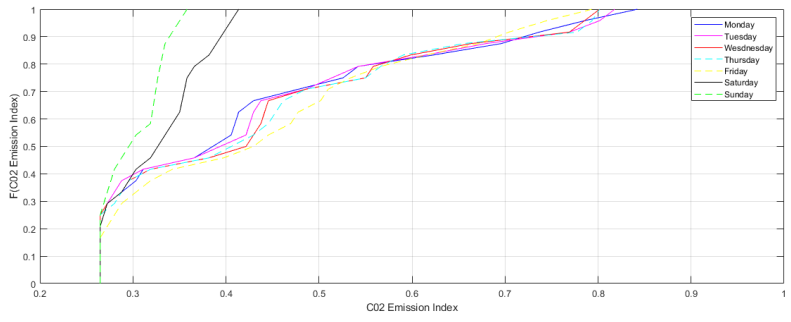

Figure 7: Cumulative distribution function of $\mathrm{CO}_{2}$ emission index in 2019

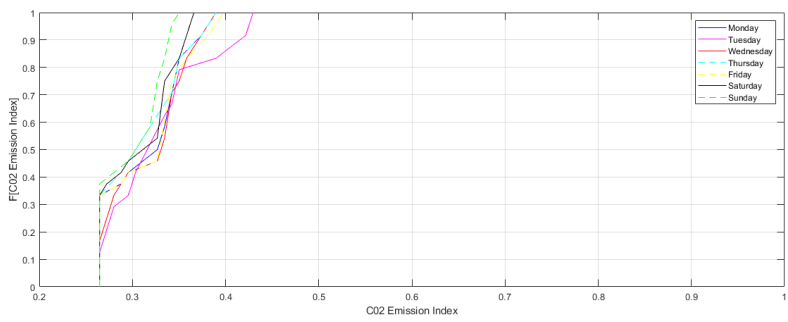

Figure 8: Cumulative distribution function of $\mathrm{CO}_{2}$ emission index during a lock-down week in 2020

\section{CONCLUSION}

The paper has presented an assessment of the impact of essential traffic on transportation systems using congestion and $\mathrm{CO}_{2}$ emission indexes for the City of Johannesburg. With more and more assessment of essential traffic, traffic management authorities can use these trends to guide future policy incentives to enhance the operational performance of mobility systems. The results also reveal in 2020 the reduced levels of emission during the national lock-down reveal if mobility in the city is restricted, this will lead to better quality of air. However, introducing a lock-down is not always an advisable option to reduce vehicular emissions as this would negatively impact economic activities. We however propose shifting commuting trips to public transportation or ridesharing services and promote online homeworking whenever possible, this would reduce the volume of traffic on highways whilst also reducing vehicular emissions. Another option could be to distribute optimally the working time to reduce morning and afternoon peaks. The investment in mining and analysing traffic data has a significantly role for future mobility planning in both the developed and developing world and, more generally, improving the quality of commuting trips in the city.

\section{ACKNOWLEDGEMENTS}

This work was funded by The National Research Foundation, South Africa (Grant No 110778) and National Research Foundation, South Africa (Grant no. 119288) 


\section{REFERENCES}

Alexander, L. P. and González, M. C., 2015. Assessing the impact of real-time ridesharing on urban traffic using mobile phone data. Proc. UrbComp pp. 1-9.

Arkatkar, S. S., 2018. Traffic operations and capacity analysis in india.

Boriboonsomsin, K., Barth, M., Zhu, W. and Vu, A., 2012. Ecorouting navigation system based on multisource historical and real-time traffic information. IEEE Trans. on Intelligent transportation Systems 13(4), pp. 1694-1704.

Bremmer, D., Cotton, K. C., Cotey, D., Prestrud, C. E. and Westby, G., 2004. Measuring congestion: Learning from operational data. Transportation Research Record 1895(1), pp. 188196.

Dias, C., Miska, M., Kuwahara, M. and Warita, H., 2009. Relationship between congestion and traffic accidents on expressways: an investigation with bayesian belief networks. In: Proceedings of 40th annual meeting of infrastructure planning (JSCE).

Furtlehner, C., Han, Y., Lasgouttes, J.-M., Martin, V., Marchal, F. and Moutarde, F., 2010. Spatial and temporal analysis of traffic states on large scale networks. In: 13th International IEEE Conference on Intelligent Transportation Systems, IEEE, pp. 12151220.

Gilbert, M., Pullano, G., Pinotti, F., Valdano, E., Poletto, C., Boëlle, P.-Y., d'Ortenzio, E., Yazdanpanah, Y., Eholie, S. P., Altmann, M. et al., 2020. Preparedness and vulnerability of african countries against importations of covid-19: a modelling study. The Lancet 395(10227), pp. 871-877.

Google, 2020. Covid-19 community mobility report.

Liu, H. X., Wu, X., Ma, W. and Hu, H., 2009. Real-time queue length estimation for congested signalized intersections. Transportation research part C: emerging technologies 17(4), pp. 412427.

Michalopoulos, P. G. and Pisharody, V. B., 1981. Derivation of delays based on improved macroscopic traffic models. Transportation Research Part B: Methodological 15(5), pp. 299-317.

Nyabadza, F., Chirove, F., Chukwu, W. C. and Visaya, M. V., 2020. Modelling the potential impact of social distancing on the covid-19 epidemic in south africa. medRxiv.

Othman, B., De Nunzio, G., Domenico, D. D. and Canudas de Wit, C., 2019. Ecological traffic management: A review of the modeling and control strategies for improving environmental sustainability of road transportation. Annual Reviews in Control 48, pp. 292-311.

Polzin, S., 2017. Vehicle miles traveled trends and implications for the us interstate highway system. Transportation Research Board, Washington, DC.

Rao, A. M. and Rao, K. R., 2012. Measuring urban traffic congestion-a review. International Journal for Traffic \& Transport Engineering.

Song, Y.-Y., Yao, E.-J., Zuo, T. and Lang, Z.-F., 2013. Emissions and fuel consumption modeling for evaluating environmental effectiveness of ITS strategies. Discrete Dynamics in Nature and Society.

Wang, H. and Fu, L., 2010. Developing a high-resolution vehicular emission inventory by integrating an emission model and a traffic model: Part 1-modeling fuel consumption and emissions based on speed and vehicle-specific power. Journal of the Air \& Waste Management Association 60(12), pp. 1463-1470.
World.Health.Organization, 2020. Coronavirus disease 2019 (covid-19): situation report, 72.

Zegeye, S. K., De Schutter, B., Hellendoorn, H. and Breunesse, E., 2009. Model-based traffic control for balanced reduction of fuel consumption, emissions, and travel time. IFAC Proceedings Volumes 42(15), pp. 149-154.

Zhao, P. and $\mathrm{Hu}, \mathrm{H} ., 2019$. Geographical patterns of traffic congestion in growing megacities: Big data analytics from beijing. Cities 92, pp. 164-174. 